\title{
Lama Penyimpanan Stek Terhadap Pertumbuhan Tanaman Ubi Kayu (Manihot esculenta Crantz)
}

\author{
Asyik Nur Allifah $\mathrm{AF}^{1}$, Muhammad Rijal ${ }^{2}$ \\ ${ }^{1,2}$ Program Studi Pendidikan Biologi IAIN Ambon \\ E-mail: asyik.nur.allifah.af@gmail.com
}

\begin{abstract}
Abstrak: Tanaman ubi kayu (Manihot esculenta Crantz) merupakan salah satu tanaman Holticultura yang dijadikan tanaman pangan dan perdagangan. Sebagai tanaman pangan, ubi kayu sumber karbohidrat bagi sekitar 500 juta manusia di dunia. Di Indonesia tanaman ubi kayu ini menempati urutan ketiga setelah padi dan jagung. Jenis penelitian ini adalah penelitian eksperimen, objek pengamatan dalam penelitian ini adalah jenis ubi kayu yang berbatang putih yang diambil pada posisi batang bagian tengah $25 \mathrm{~cm}$ dari pangkal batang dan $25 \mathrm{~cm}$ dari ujung batang yang disimpan dengan lama penyimpanan yang berbeda. Hasil penelitian menunjukan bahwa lama penyimpanan berpengaruh pada taraf 5\% dan $1 \%$ terhadap pertumbuhan ubi kayu. Berdasarkan uji beda menyatakan bahwa $\mathrm{P}_{1}$ berbeda bila dibandigkan dengan perlakuan lainnya, dengan tinggi tanaman untuk $P_{1}=29,9 \mathrm{~cm}$ dengan jumlah daun 17,7 helai. Hasil pengamatan bahwa lama penyimpanan stek terhadap pertumbuhan tanaman ubi kayu pada tahap perlakuan tanpa penyimpanan dengan rataan perlakuan adalah $29,9 \mathrm{~cm}$, penyimpanan satu minggu 24,23 $\mathrm{cm}$ dan penyimpanan dua minggu $22,5 \mathrm{~cm}$
\end{abstract}

\section{Kata Kunci: Lama Penyimpanan Stek, Tinggi Tanaman, Jumlah Daun}

\section{LONG STORAGE CUTTINGS ON THE GROWTH OF CASSAVA}

\begin{abstract}
Plant cassava (Manihot esculenta Crantz) is one of plants holticultura as food crops and trade. As a food plant, cassava sources of carbohydrate for about 500 million people in the world. In Indonesia plant cassava is ranked third after rice and corn. The research is research experiment, the object of the research is kind of cassava white herbs taken at the stem the middle of 25 inches from the base of the stem and 25 inches from the end of a stem kept with long storage different. The results showed that affects long storage standard $5 \%$ and $1 \%$ on the growth of cassava. Based on the different said that if $\mathrm{P} 1$ different with other treatment, with high plants to $\mathrm{P} 1=29,9 \mathrm{~cm}$ and of leaves 17,7 strands. The results of the observation that long storage graft on the growth of plants cassava at the treatment without storage with average the treatment is $29,9 \mathrm{~cm}$, storage one week $24.23 \mathrm{~cm}$ and storage two weeks $22.5 \mathrm{~cm}$
\end{abstract}

Key Words: Long Storage Cuttings, Tall Plant, Number Of Leaves

BIOLOGI SEL (VOL 7 NO 2 EDISI JUN-DES 2018 ISSN 2252-858X/E-ISSN 2541-1225)PAGE 118 
Ubi kayu merupakan tanaman pangan dan perdagangan (cash crop).Sebagai tanaman perdagangan, ubi kayu menghasilkan starch, garpek, tepung ubi kayu, etanol, gula cair, sarbitol, monosodiumglutamat, tepung aromatik, dan pelets. Tanaman pangan ubi kayu merupakan sumber karbohidrat bagi sekitar 500 juta jiwa manusia di dunia. Di Indonesia tanaman ini menempati urutan ke tiga setelah padi dan jagung. Sebagai sumber karbohidrat, ubi kayu merupakan penghasil kalori terbesar di bandingkan dengan tanaman lain seperti jagung, beras, sorgum dan gandum.

Di dunia tanaman ubi kayu (Manihot esculenta Crantz) telah di budidayakan sekitar 7000 tahun silam, tetapi tanaman ini baru masuk ke indonesia kurang lebih pada abad ke-17 yang dibawah oleh pedagang Portugis (Margiono dkk, 1986). Indonesia merupakan penghasil ubi kayu terbesar ke empat setelah Nigeria, Brazil dan Thailand. Namun pasar ubi kayu di dunia dikuasai oleh thailanddan Vietnam (Rama.P dkk, 2007). Ubi kayu mempunyai banyak nama, yaitu ketela, keutila, ubi kayee (A-ceh), ubi parancih (Minangkabau), ubi singkung (Jakarta), batata kayu (Manado), bistungkel (Ambon), huwi dangdeur (Sunda), tela pohung (Jawa), tela balandha (Madura), sabrang sawi (Bali), kasubi (Gorontalo), lame kayu (Makassar), lame aju (Bugis), kasibi (Ternate, Tidore) (Purwono, 2009).

Ubi kayu termasuk tanaman tropis, tetapi dapat pula beradaptasi dan tumbuh dengan baik di daerah sub tropis. Secara umum tanaman ini tidak menuntut iklim yang spesifik untuk pertumbuhannya Jones dalam Yuliawati (2009).Ubi kayu dapat tumbuh dengan baik ditempat padi dan jagung tumbuh tidak baik.Ubi kayu juga dikenal sebagai tanaman yang mampu tumbuh pada lahan-lahan marginal, tetapi produktifitasnya sangat dipengaruhi oleh kesuburan tanah.Yuliawati, (2009) menambahkan, ubi kayu akan tumbuh dengan baik pada daerah dibawah $1.500 \mathrm{~m}$ dpl dengan curah hujan 750-1.000 $\mathrm{mm} /$ tahun dan suhu rata-rata $25-28{ }^{\circ} \mathrm{C}$. Tanah yang baik untuk pertumbuhannya adalah tanah lempung berpasir yang cukup hara dan berstruktur gembur.Namun, dapat pula tumbuh pada tanah dengan tekstur berpasir hingga liat.

Keunggulan tanaman ubi kayu dibandingkan tanaman pertanian lain seperti padi dan jagung adalah mudah untuk dibudidayakan, tahan terhadap serangan hama dan penyakit, mampu bertahan pada kondisi kekurangan air atau curah hujan yang rendah, dapat berproduksi dengan baik di tanah yang miskin hara. Selain itu umbinya dapat diolah menjadi berbagai produk seperti gaplek, tepung tapioka, tapai dan keripik. (Elida dan Hamidi, 2009)

Peningkatan hasil pertanian yang mantap memiliki peranan penting dalam memenuhi kebutuhan masyarakat, juga dapat meningkatkan ekonomi petani ubi kayu. Pembibitan tanaman dapat dilakukan secara generatif (dengan biji) maupun secara vegetatif (dengan penyetekan). Penyetekan merupakan suatu perlakuan pemisahan atau pemotongan bagian dari tanaman seperti akar batang dan tunas dengan maksud agar bagian-bagian tersebut membentuk akar. Cara stek memiliki beberapa kelebihan 
diantaranya dapat menghasilkan tanaman yang memiliki akar, batang dan daun yang sifatnya sama dengan induknya, serta lebih cepat bereproduksi dibanding dengan menggunakan biji, (Wudianto, 1993).

Ubi kayu termasuk kedalam kelas Dicotyledoneae yang artinya tanaman ubi kayu termasuk salah satu jenis tanaman yang memiliki kambium pada batangnya, yang memungkinkan perkembangbiakkan dengan cara stek pada bagian batangnya. Batang dapat digunakan sebagai stek apabila masa penyimpanannya kurang dari 30 hari setelah panen. Pada beberapa kultivar, seperti Rayong 3 dan Rayong 90, masa simpan stek selama 15 hari setelah panen. Penyimpanan stek yang baik adalah dengan cara posisi batang tegak, disimpan di bawah naungan. (Wargiono, 1979).

Cara stek banyak dipilih karena bahan yang dibutuhkan sedikit dan dapat memperoleh bibit tanaman dalam jumlah banyak.Tanaman stek biasanya memiliki persamaan dalam umur, ukuran tinggi, ketahanan terhadap penyakit, dan sifat lainnya (Pertiwi dan Pracaya, 1992). Kualitas bibit asal stek dipengaruhi banyak faktor, diantaranya adalah lama penyimpanan, cara penyetekan, bahan stek, cara potongan, bagian stek yang tertanam dan menggunakan Zat Pengatur Tumbuh (Pertiwi dan Pracaya, 1992).

Dalam penelitian yang di lakukan oleh Hidayat, (2009).Pada stek tanaman vanili membuktikan bahwa lama penyimpanan stek berpengaruh terhadap pertumbuhan tanaman vanili tersebut. Dalam penelitiannya dia menggunakan lama penyimpanan yang berbeda yakni: 0 hari, 8 hari, 12 hari, dan 16 hari. Hasil penelitian menunjukan lama penyimpanan terbaik di peroleh dari perlakuan lama penyimpanan 8 hari. Pada perlakuan lama penyimpanan, panjang tunas tertinggi dan jumblah daun terbnyak di peroleh dari lama penyimpanan 8 hari yakni $71,2 \mathrm{~cm}$ dan 10 helai daun.

\section{METODE PENELITIAN}

Jenis penelitian yang digunakan dalam penelitian ini adalah eksperimen lapangan dengan menggunakan Rancangan Acak Lengkap (RAL) yang terdiri dari 3 perlakuan yakni P1 tanpa penyimpanan, P2 disimpan selama 1 minggu dan P3 disimpan selama 2 minggu. Dengan masing-masing 3 kali ulangan. Jadi terdapat 9 unit percobaan guna mengetehui pengaruh lama penyimpanan terhadap pertumbuhan tanaman ubi kayu (Manihot esculenta Crantz).

Adapun objek dalam penelitian ini adalah stek ubi kayu jenis Manihot esculenta Crantz yang berbatang putih yang berumur tiga bulan yang di ambil dari kebun rakyat pada posisi batang bagian tengah, $25 \mathrm{~cm}$ dari pangkal batang dan $25 \mathrm{~cm}$ dari ujung batang. Variabel dalam penelitian ini terbagi dua yaitu Variabel bebas: lama penyimpanan dan Variabel terikat: Tinggi tanaman dan jumlah daun. Untuk memperoleh data yang akurat harus memperhatikan langka-langka sebagai berikut: 
1. Menyiapkan semua alat dan bahan yang diperlukan

2. Tanah diolah menjadi guludan dengan cara di cangkul setinggi $20 \mathrm{~cm}$

3. Pilih batang tanaman ubi kayu yang memenuhi persyaratan sebagai bibit (umur 3 bulan)

4. Siapkan kayu untuk alas batang ubi kayu yang akan dipotong dengan menggunakan parang

5. Stek ubi kayu dipotong pada bagian tengah sepanjang $25 \mathrm{~cm}$ dari pangkal batang dan $25 \mathrm{~cm}$ dariujung batang.

6. Stek ubi kayu disimpan di tempat yang ternaungi dengan posisi batang tegak sesuai perlakuan penyimpanan yaitu

a. Tanpa penyimpanan

b. Disimpan selama satu minggu

c. Disimpan selama dua minggu

7. Stek ditanam pada guludan yang telah di siapkan.

8. Pengamatan di lakukan 2 minggu setelah di tanam dan akan dilakukan pengamatan lanjutan setiap 2 minggu sekali sekaligus dilakukan penyiangan (pembersihan) terhadap tumbuhan penggangu.

Untuk mengetahui adanya pengaruh yang signifikan, maka dilakukan analisis data dengan menggunakan Analisis of Varians (ANOVA). Jika $F_{\text {hitung }}>F_{\text {tabel }}$ pada taraf signifikan $1 \%$ dan 5\% maka hipotesis $\mathrm{H} 1$ diterima dan $\mathrm{H} 0$ ditolak. Sebaliknya jika $\mathrm{F}_{\text {hitung }}$ $<\mathrm{F}_{\text {tabel }}$ pada taraf signifikan 5\% dan 1\% maka hipotesis $\mathrm{H} 1$ ditolak dan $\mathrm{H} 0$ diterima. Jika hasil analisis menunjukan perbedaan nyata (signifikan pada taraf 5\%) maka dilanjutkan dengan uji Beda Nyata Terkecil (BNT) untuk mengetahui derajat beda antar kelompok perlakuan.

\section{HASIL DAN PEMBAHASAN}

Hasil penelitian menunjukkan bahwa lama penyimpanan stek berpengaruh terhadap tinggi tanaman dan jumlah daun tanaman ubi kayu (Manihot eskulenta Crantz.). Demikian juga secara statistik menunjukkan pengaruh yang nyata $F_{\text {hitung }}>F_{\text {tabel. }}$ Rataan tinggi tanaman dan jumlah daun dapat dilihat pada Tabel 1 berikut:

Tabel 1. Rataan Tinggi Tanaman, Jumlah Daun, dan Bobot Segar Tanaman Ubi Kayu

(Manihot esculenta Crantz.) Selama Penelitian

\begin{tabular}{|c|c|c|}
\hline Perlakuan & $\begin{array}{c}\text { Tinggi Tanaman } \\
(\mathrm{cm})\end{array}$ & $\begin{array}{c}\text { Jumlah Daun } \\
\text { (helai) }\end{array}$ \\
\hline $\mathrm{P}_{1}$ & 29,9 & 18 \\
\hline $\mathrm{P}_{2}$ & 24,23 & 14 \\
\hline $\mathrm{P}_{3}$ & 22,5 & 14 \\
\hline
\end{tabular}

Sumber: Hasil Penelitian, 2016

Tabel diatas menunjukkan bahwa pertumbuhan tanaman ubi kayu (Manihot eskulenta Crantz.) pada tinggi tanaman dan jumlah daun pada perlakuan lama 
penyimpanan stek, denga 3 perlakuan yang berbeda menunjukan hasil yang terbaik pada akhir pengamatan terdapat pada perlakuan $\mathrm{P}_{1}$, dibandingkan dengan perlakuan yang lain. Di mana pada tinggi tanaman dengan perlakuan $\mathrm{P}_{1}$ (tanpa penyimpanan) $29,9 \mathrm{~cm}$ dan jumlah daun 18 helai

\section{Tinggi Tanaman}

Dari pengamatan yang dilakukan selama 3 bulan terhadap keseluruhan sampel yang memiliki perlakuan yang berbeda-beda yakni tanpa penyimpanan $\left(\mathrm{P}_{1}\right)$, satu minggu $\left(\mathrm{P}_{2}\right)$ dan penyimpanan dua minggu $\left(\mathrm{P}_{3}\right)$ maka diperoleh variasi hasil pengamatan yang sangat signifikan pada pertumbuhan tinggi tanaman antara semua sampel yang diteliti seperti yang terlampir pada tabel di bawah ini

Tabel 2. Rataan Tinggi Tanaman/Minggu Pada Perlakuan Lama Penyimpanan Stek yang

Berbeda $(\mathrm{cm})$

\begin{tabular}{|c|c|c|c|c|c|c|}
\hline \multirow{2}{*}{ Perlakuan } & \multicolumn{4}{|c|}{ Minggu setelah tanam (MST) } & \multirow{2}{*}{ Jumlah } & \multirow{2}{*}{ Rataan } \\
\hline & M2 & M4 & M6 & M8 & & \\
\hline $\mathrm{P}_{1}$ & 11 & 21 & 37,3 & 50,3 & 119,6 & 29,9 \\
\hline $\mathrm{P}_{2}$ & 9,6 & 19,3 & 28,5 & 39,5 & 96,9 & 24,23 \\
\hline $\mathrm{P}_{3}$ & 8,5 & 17,6 & 26,6 & 37,3 & 90 & 22,5 \\
\hline
\end{tabular}

Sumber: Hasil Penelitian, 2016

Ket: $\mathrm{P}_{1=}$ tanpa penyimpanan, $\mathrm{P}_{2}=$ penyimpanan 1 minggu, $\mathrm{P}_{3=}$ penyimpanan 2 minggu

Pada tabel 2 menunjukan bahwa perlakuan lama penyimpanan stek ubi kayu pada perlakuan $P_{1}$ (tanpa penyimpanan) menunjukan pertumbuhan yang lebih baik bila dibandingkan dengan kedua lama penyimpanan yang lainnya.Adapun perlakuan $\mathrm{P}_{1}$ menunjukan tinggi tanamana dalah $29,9 \mathrm{~cm}$. Pada perlakuan $P_{2}$ menunjukan pertumbuhan yang agak lambat $(24,23)$ berbeda dengan $P_{3}$. Adapun pertumbuhan tinggi tanaman pada perlakuan $P_{3}$ adalah $22,5 \mathrm{~cm}$. Berdasarkan hasil uji sidik ragam menunjukkan bahwa perlakuan lama penyimpananstek yang berbeda menghasilkan pengaruh sangat nyata pada tinggi tanaman yang di hubungkan dengan nilai $\mathrm{F}_{\text {hitung }}>$ nilai $\mathrm{F}_{\text {tabel }}$ pada tingkat kepercayaan 5\% $(5,14)$ dan tingkat kepercayaan $1 \%(10,99)$ pada minggu I sampaiIV pengamatan dengan nilai $\mathrm{F}_{\text {hitung }}>$ nilai $\mathrm{F}_{\text {tabel }}$ dan dilanjutkan dengan uji beda nyata terkecil (BNT) dengan tarab 5\% dapat di lihat pada Tabel 3 di bawah ini.

Tabel 3. Nilai Beda Masing-Masing Perlakuan Berdasarkan Uji Beda Nyata Terkecil

Pada Taraf $5 \%$ dan $1 \%$

\begin{tabular}{|c|c|c|c|c|}
\hline Perlakuan & Rata-rata & Nilai beda & BNT taraf $5 \%$ & Taraf $1 \%$ \\
\hline $\mathrm{P}_{1}$ & 29,9 & $7,4^{* *}$ & & \\
\hline $\mathrm{P}_{2}$ & 24,23 & $1,73^{\text {tn }}$ & 4,16 & 6,30 \\
\hline $\mathrm{P}_{1}$ & 22,5 & & & \\
\hline
\end{tabular}

Keterangan: sangat nyata $(* *)$ dan Tidak nyata $\left({ }^{\mathrm{tn}}\right)$

\section{Jumlah Daun}

Berdasarkan hasil pengamatan dengan menggunakan 3 perlakuan yang berbeda menunjukkan nilai rata-rata jumlahd aun yang berbeda dapat dilihat pada Tabel 4 berikut: Tabel 4. Rataan Jumlah Daun Seteleh Penelitian (helai) 


\begin{tabular}{|l|l|l|l|l|l|l|}
\hline \multirow{2}{*}{ Perlakuan } & \multicolumn{3}{|l|}{ Minggusetelahtanam (MST) } & \multirow{2}{*}{ Jumlah } & \multirow{2}{*}{ Rataan } \\
\cline { 2 - 7 } & M2 & M4 & M6 & M8 & & \\
\hline $\mathrm{P}_{1}$ & 8 & 15 & 18 & 29 & 70 & 17 \\
\hline $\mathrm{P}_{2}$ & 6 & 12 & 17 & 22 & 57 & 14 \\
\hline $\mathrm{P}_{3}$ & 7 & 12 & 15 & 20 & 54 & 13 \\
\hline
\end{tabular}

Sumber: Hasil Penelitian, 2016

Tabel tersebut, menunjukan bahwa pada perlakuan lama penyimpanan stek terhadap jumlah daun yang terbaik pada minggu terakhir adalah pada perlakuan $\mathrm{P}_{1}$ yaitu sebesar 17 helai dan paling terendah jumlah daunnya 13 helai di bandingkan dengan perlakuan yang lain. Berdasarkan hasil uji sidik ragam menunjukan bahwa perlakuan lama penyimpanan stek dengan lama penyimpanan yang berbeda menghasilkan pengaruh yang tidak nyata terhadap jumlah daun dan di hubungkan dengan nilai $F_{\text {hitung }}<$ nilai $F_{\text {tabel }}$ (11-18).

Pertumbuhan tanaman merupakan konsep universal dalam biologi dan merupakan hasil dari berbagai proses fisiologis yang berinteraksi dalam tubu htanaman bersama factor luar. Ketiga proses tersebut yaitu pertambahan ukuran, bentuk dan jumlah (Sitompul dan Guritno, 1994). Pertumbuhan tanaman yang di amati dalam penelitian ini adalah tinggi tanaman dan jumlah daun. Hasil analisis ragam menunjukkan bahwa, lama penyimpanan stek berpengaruh sangat nyata terhada ppertumbuhan tanaman ubi kayu (Manihot esculenta Crantz) yang ditentukan dengan pertumbuhan tinggi tanaman dan jumlah daun tanaman. Berdasarkan hasil penelitian dapat kita lihat bahwa perlakuan $\mathrm{P}_{1}$ sangat berpengaruh nyata terhadap jumah daun dan tinggi tanaman hal ini diakibatkan karena stek yang di berikan perlakuan penyimpanan akan mengalami penguapan sehingga kandungan nitrogen dan karbohidat menjadi berkurang yang berdampak pada keterlambatan pertumbuhan tunas (Mahistede dan Haber, 1957)

Berdasarkan hasil penelitian menunjukan bahwa tanaman stek ubi kayu tanpa disimpan $\left(P_{1}\right)$ 29,9 cm menunjukan tinggi tanaman lebih tinggi jika dibandingkan dengan penyimpanan $1 \operatorname{minggu}\left(P_{2}\right) 24,23 \mathrm{~cm}$ dan $2 \operatorname{minggu}\left(P_{3}.\right) 22,5 \mathrm{~cm}$. hal ini disebabkan karna tanpa penyimpanan kandungan sesulosa pada ubi kayu masi tersedia cukup banyak, ini merupakan enerzi cadangan yang dipakai oleh ubi kayu untuk merangsang terbentuknya akar pada setek ubi kayu sehingga memungkinkan penyerapan unsur hara yang lebih cepat jika dibandingkan dengan perlakuan $\mathrm{P}_{2}$ dan $\mathrm{P}_{3}$. Sedangkan untuk perlakuan $\mathrm{P}_{2}$ maupun $\mathrm{P}_{3}$ penyimpanan itu membawa pengaruh pada pemakaian selulosa sebagai cadangan makanan akibatnya pada proses penanaman akar lambat karna energinya sudah dipakai untuk penyimpanan.

Berdasarkan uji statistik terhadap tinggi tanaman ubi kayu menunjukkan terdapat pengaruh yang sangat signifikan pada minggu terakhir pengamatan dengan $F_{\text {hitung }}>F_{\text {tabel }}$ pada taraf $5 \%(5,14)$ dan $1 \%(10,99)$ dan beda nyata antara perlakuan berdasarkan uji BNT taraf 5\% $(4,16)$ dan 1\% (6,30). Menurut Gardner, Pearce dan Mitchell (1991) 
mengatakan pada meristem ujung akar dan batang menghasilkan sel-sel baru sehingga tanaman bertambah tinggi atau panjang. Menurut Kusumo (1989), pembelahan sel distimulasi oleh aktifnya amylase menghidrolisis pati menjadi gula tereduksi sehingga konsentrasi gula meningkat akibatnya tekanan osmotic juga meningkat. Peningkatan tekanan osmotik di dalam sel menyebabkan air mudah masuk ke dalam sel, sehingga dapat melakukan segala proses fisiologis dalam sel tanaman.

Selain rendahnya pertumbuhan tinggi tanaman pada $\mathrm{P}_{2}$ dan $\mathrm{P}_{3}$ diduga karena terjadinya proses plasmolysis dimana proses sel-sel kehilangan air dalam hipertonik solusi, Jika sel tumbuhan ditempatkan dalam hipertonik solusi, sel tumbuhan kehilangan air dan karenanya turgor tekanan oleh plasmolisis: tekanan menurun ketitik di mana protoplasma dari kulit sel dari dinding sel, meninggalkan kesenjangan antara dinding sel dan membrane dan membuat sel tanaman lembek.

Secara umum daun dapat dipandang sebagai organ produsen fotosintat utama, maka pengamatan daun sangat diperlukan selain indikator pertumbuhan juga sebagai data penunjang proses pertumbuhan yang terjadi pada pembentukan biomasa tanaman pengamatan daun dapat didasarkan atas fungsinya sebagai penerima cahaya alat fotosintesis (Sitompul dan Guritno, 2002).

Tanaman stek ubi kayu pada daun tanpa disimpan nilai $\left(\mathrm{P}_{1}\right)$ menunjukan jumlah daun lebih banyak jika dibandingkan dengan penyimpanan 1 minggu $\left(\mathrm{P}_{2}\right)$ dan penyimpanan 2 minggu $\left(\mathrm{P}_{3}\right)$. Hal ini disebabkan karna tanpa penyimpanan kandungan air dan pati pada batang setek ubi kayu masih tersedia cukup banyak sehingga merangsang sel-sel somatik untuk kembali bersifat meristematis untuk membentuk tunas atau daun baru, pada saat tanaman tersebut dipotong maka akan mulai terjadi inisiasi, pada daerah pemotongan itu akan terjadi diferensiasi (pembelahan sel). Hardmann (2002). Seperti penelitian yang dilakukan oleh Hetty terhadap pertumbuhan stek ubi jalar disitu dia mendapati bahwa kontrol $\left(\mathrm{B}_{1}\right)$ tanpa disimpan mempunyai hasil yang lebih baik bila dibandingkan dengan perlakuan lainnya. (Hetty, 2008) Jika dibandingkan dengan perlakuan $\mathrm{P}_{2}$ dan $\mathrm{P}_{3}$. Sedangkan untuk perlakuan $\mathrm{P}_{2}$ maupun $\mathrm{P}_{3}$ penyimpanan itu membawa pengaruh pada pemakaian air dan pati akibatnya pada proses penanaman pembentukan daun menjadi lebih lambat.

Berdasarkan uji statistik terhadap jumlah daun tanaman ubi kayu menunjukan terdapat pengaruh yang sangat signifikan pada minggu terakhir pengamatan dimana $F_{\text {hitung }}$

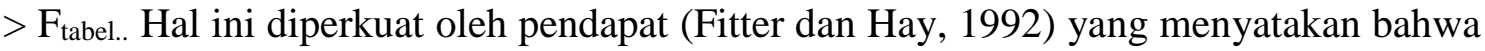
laju pertumbuhan sel-sel tanaman dan efisiensi proses fisiologi dapat terjadi apabila selsel tanaman mendapat air.

\section{KESIMPULAN}

Berdasarkan hasil penelitian ini, dapat disimpulkan bahwa lama penyimpanan stek sangat berpengaruh nyata terhadap pertumbuhan tinggi tanaman ubi kayu dimana 
kontrol $\mathrm{P}_{1}$ lebih dominan dari perlakuan lainnya. Yang dibuktikan dengan uji sidik ragam dimana nilai $F_{\text {hitung }}>F_{\text {tabel. }}$ Lama penyimpanan stek tidak berpengaruh terhadap pertumbuhan jumlah daun tanaman ubi kayu yang dibuktikan pada uji sidik ragam dimana nilai $F_{\text {hitung }}<$ nilai $F_{\text {tabel. }}$

\section{SARAN}

Berdasarkan hasil penelitian yang didapat, disarankan kepada para petani ubi kayu agar ketika ingin bercocok tanam ubi kayu jenis Manihot esculenta Cranz sebaiknya langsung ditanam agar hasil yang didapat akan memuaskan

\section{DAFTAR PUSTAKA}

Cahyono, 2009. Ubi Kayu Budidaya Dan Usaha Tani. Penerbit Kanisius. Yogyakarta

Dep. Kes RI. 1981. Daftar Komposisi Bahan Makanan. Direktorat Gizi Departemem

Kesehatan RI. Bharatara Karya Aksara. Jakarta.

Elide S, Hamidi W. 2009. Analisis Pendapatan Agroindustri Rengginang Ubi Kayu Di Kabupaten Kampar. Pekanbaru. Fakultas Pertanian UIR

Taufik Hidayat. 2009. Balai Pengkajian Teknologi Pertanian Di Kabupaten Semarang Kota Bengkulu. Bengkulu

Heddy. S. 1989. Biologi Pertanian. Rajawali Press Jakarta

Ir. Bambang Cahyono. 2004. Aneka Produk Olahan Ubi Kayu. Aneka Ilmu. Semarang.

Kartasapoetra, W.A.G. 1989. Kerusakan Tanah Pertanian. Bina Aksara. Jakarta

Naiola, 1986. Tanaman Budidaya Indonesia. CV Yasaguna. Jakarta

Pertiwi dan Pracaya. 1992. Teknik Melipatgandakan Hasil Tanaman Diareal Sempit. CV. Bahagia. Pekalongan

Rahmat Rukmana. 1997. Ubi Kayu, Budi Daya dan Pascapanen. Kanisius. Yogyakarta. Rochiman Dan Harjadi. 1973. Pembiakan Vegetatif. Departemen Agronom Fakultas Pertanian IPB. Bogor

Suprapti.L. 2005. Pembuatan Tepung Terigu Dan Pemanfaatannya. Kanisius. Yogyakarta

Tjitrosoepomo. 1991. Botani Umum. UGM Press. Yogyakarta

Yuliawati, 2009. Pengolahan Tanaman Dan Organism Pengganggu Tanaman (OPT) Ubi

Kayu, Di Kecamatan Ciamis, Sukabumi Dan Kecamatan Dramaga, Bogor. (Skripsi) Fakultas Pertanian, Institut Pertanian Bogor.

Wargiono, J. 1979. Ubi kayu dan Cara Bercocok Tanam. Buletin Teknik No.4.36p. Bogor:

Lembaga Pusat Penelitian Pertanian Bogor.

Wugianto. 1993. Membuat Stek, Cangkok dan Okulasi. PT Penebar Swadaya. Jakarta Harjadi, M.M.S.s. 1996. Pengantar Agronomi. PT. Gramedia Pustaka Utama. Jakarta Fitter, A.H and R.K.M. Hay. 1991. Fisiologi Lingkungan Tanaman. Terjemahan S. Andani dan E.D. Purbayanti. UGM-press. Yogyakarta 
Ashari, S. 2006. Hortikultura Aspek Budidaya. UI-Press. Jakarta

Wudianto, R. 2002. Membuat Setek, Cangkok dan Okulasi. Penebar Swadaya. Jakarta 